\title{
The Role Of Progestogens In Threatened And Idiopathic Recurrent Miscarriage
}

This article was published in the following Dove Press journal:

International Journal of Women's Health

\author{
Hisham Arab' \\ Ahmed Jaber Alharbi ${ }^{2}$ \\ Ayman Oraif $^{3}$ \\ Emad Sagr ${ }^{4}$ \\ Hana Al Madani ${ }^{5}$ \\ Hassan Abduljabbar $\mathbb{D}^{3}$ \\ Osama Sadeak Bajouh ${ }^{3}$ \\ Yaser Faden ${ }^{6}$ \\ Yasser Sabr (iD) \\ 'Obstetrics and Gynecology \\ Department, Dr. Arab Medical Center. \\ Jeddah, Saudi Arabia; ${ }^{2}$ Obstetrics and \\ Gynecology Department, Ibinsina Medical \\ Private College, Jeddah, Saudi Arabia; \\ ${ }^{3}$ Department of Obstetrics and \\ Gynecology, King Abdulaziz University, \\ Jeddah, Saudi Arabia; ${ }^{4}$ Obstetrics and \\ Gynecology Department, The \\ International Medical Center, Jeddah, \\ Saudi Arabia; ${ }^{5}$ Obstetrics and \\ Gynecology Department, Maternity \\ Hospital - King Saud Medical City, \\ Riyadh, Saudi Arabia; ' ${ }^{6}$ epartment of \\ Obstetrics and Gynecology, King Saud bin \\ Abdulaziz University for Health Sciences - \\ Ministry of National Guard Health Affairs, \\ Jeddah, Saudi Arabia; ${ }^{7}$ Maternal Fetal \\ Medicine Division, Department of \\ Obstetrics and Gynecology, College of \\ Medicine, King Saud University, King Khalid \\ University Hospital, Riyadh, Saudi Arabia
}

Correspondence: Hisham Arab Obstetrics and Gynecology Department, Dr. Arab Medical Center, P.O. Box 17440, Jeddah 2 I 484, Saudi Arabia

Tel +966 I2 2832III

Email arab|23@gmail.com

\begin{abstract}
It is well known that progesterone plays a major role in the maintenance of pregnancy, particularly during the early stages, as it is responsible for preparing the endometrium for implantation and maintenance of the gestational sac. The management of pregnant women at risk of a threatened or idiopathic recurrent miscarriage is complex and critical. Therefore, a group of obstetricians and gynecologists practicing in Saudi Arabia gathered to update the 2014 Saudi guidelines for threatened and recurrent miscarriage management. In preparation, a literature review was conducted to explore the role of oral, vaginal, and injectable progestogens: this was used as a basis to develop position statements to guide and standardize practice across Saudi Arabia.
\end{abstract}

Keywords: idiopathic recurrent miscarriage, progesterone, progestin, progestogen, Saudi Arabia, threatened miscarriage

\section{Introduction}

It is estimated that about $70 \%$ of conceptions are lost prior to live birth: $30 \%$ due to implantation failure, $30 \%$ following implantation but before a missed period, and about $10 \%$ as clinical miscarriage. ${ }^{1}$ Despite considerable advances in science and technology, preventing and managing patients at risk of clinical miscarriage in early pregnancy continues to be a distressing problem. ${ }^{2}$ The possible causes of miscarriage, which can be broadly divided into two categories, are listed in Table $1 .^{2-4}$

\section{The Role Of Hormones In Pregnancy}

Pregnancy is a hormone-mediated physiological state that involves a decrease in uterine vascular tone and an increase in uterine blood flow. ${ }^{5}$ Progesterone and estrogen are two key hormones that remain elevated during pregnancy and play significant roles in causing anatomical adjustments within the uterus to create an environment conducive to fetal growth. ${ }^{5}$

Progesterone, rightly called the "pregnancy hormone", is crucial in the maintenance of pregnancy as it is involved in modulation of the maternal immune response, suppression of inflammatory response, reduction of uterine contractility, improvement of utero-placental circulation, and luteal-phase support. ${ }^{6}$ Particularly in early pregnancy, progesterone is responsible for preparing the endometrium for implantation and maintenance of the gestational sac in the uterus. ${ }^{7}$

\section{Mechanisms Involved In Miscarriage}

Considerable progress has been made in the fields of cytogenetics and immunogenetics, which has in turn contributed to a better understanding of the mechanisms 
Table I Causes Of Miscarriage

\begin{tabular}{|l|l|}
\hline Categories & Features \\
\hline Abnormal embryo & Structural anomalies incompatible with life \\
\cline { 2 - 3 } & $\begin{array}{l}\text { Chromosomal abnormalities: trisomy, } \\
\text { polyploidy, monosomy X, structural } \\
\text { abnormalities of individual chromosomes }\end{array}$ \\
\hline Hostile maternal & $\begin{array}{l}\text { Uterine abnormalities: congenital anomalies, } \\
\text { adhesions, leiomyoma }\end{array}$ \\
\cline { 2 - 3 } & $\begin{array}{l}\text { Infection: bacterial vaginosis, toxoplasmosis, } \\
\text { listeriosis, chlamydia, gonorrhea, rubella }\end{array}$ \\
\cline { 2 - 3 } & $\begin{array}{l}\text { Chronic maternal disease: poorly controlled } \\
\text { diabetes, celiac disease }\end{array}$ \\
\cline { 2 - 3 } & $\begin{array}{l}\text { Immune dysfunction: antiphospholipid } \\
\text { antibody syndrome and thyroid autoimmunity }\end{array}$ \\
\cline { 2 - 3 } & $\begin{array}{l}\text { Endocrine: absence of proper progesterone } \\
\text { concentration, thyroid hormone levels }\end{array}$ \\
\hline
\end{tabular}

Note: Data from Larsen et $\mathrm{al}^{2}$, Griebel et $\mathrm{al}^{3}$ and Zhang et al. ${ }^{4}$

involved in miscarriage. ${ }^{2}$ The main mechanisms involved in early miscarriage include chromosomal abnormalities or aberrations, immunological and immunogenetic causes, thrombophilias, endocrinological disorders, sperm DNA fragmentation, failure of embryo selection, uterine malformations, hCG gene polymorphisms and epigenetic causes, and lifestyle factors. ${ }^{2}$ Fetal malformations were found to be responsible for $85 \%$ of early clinical miscarriages, with chromosomal abnormalities found in one partner of 3-6\% of couples experiencing a recurrent miscarriage, which is ten times higher than the rate in the general population. ${ }^{2}$ Cytokine-mediated immunological reactions are estimated to be responsible for $40-60 \%$ of all cases of idiopathic recurrent spontaneous miscarriages. ${ }^{8}$

In recent years, it has become increasingly clear that maternal immune tolerance of the fetus is key to promoting fetal survival. ${ }^{9}$ It has been suggested that successful pregnancy is associated with downregulation of Th1-type activity and enhancement of Th2-type activity. ${ }^{8}$ Studies have reported that women with spontaneous recurrent miscarriages have elevated levels of the Th1 cytokines interleukin (IL)-2 and interferon- $\gamma$ and decreased levels of the Th2 cytokine IL-10, as assessed by antigen- and mitogen-induced activation of peripheral blood mononuclear cells. ${ }^{8}$ Progesterone favors the development of human T-cells producing Th2 cytokines and blocks the production of Th1 cytokines, indicative of its role in pregnancy maintenance. ${ }^{8}$

\section{Terminology}

At present, there is no consensus on the number of miscarriages needed to fulfill the criteria for recurrent miscarriage; however, this group of experts from Saudi Arabia agreed to follow the guidelines proposed by the European Society of Human Reproduction and Embryology (ESHRE), which define recurrent miscarriage as "the loss of two or more pregnancies". ${ }^{10}$ A "biochemical loss" is defined as a miscarriage that occurs (usually before 6 weeks of gestation) following a positive urinary human chorionic gonadotropin (hCG) or a raised serum $\beta$-hCG, but prior to ultrasound or histological verification. ${ }^{2}$ The term clinical miscarriage is used when ultrasound examination or histological evidence has confirmed that an intrauterine pregnancy has existed. ${ }^{2}$ Clinical miscarriages may be subdivided into early (before gestational week 12) and late (gestational weeks 12 to 21$)^{2}$

As per the expert panel, patients with a biochemical and ultrasound confirmation of pregnancy depicting the clinical signs of threatened miscarriage should be thoroughly investigated prior to prescribing treatment.

\section{Materials And Methods}

A group of nine obstetricians and/or gynecologists, each with over 10 years of clinical practice experience in Saudi Arabia, met on November 15, 2018, and January 31, 2019 , in Jeddah, Saudi Arabia, with the objective of updating the current Saudi guidelines for threatened and recurrent miscarriage management, ${ }^{11}$ which were published in 2014. During the first meeting, the initial guidelines were reviewed, recent updates in clinical practice identified, and gaps in practice enumerated. Based on this evaluation, the expert panel took 2 months to conduct a literature review on the role of oral, vaginal, and injectable progestogens in early pregnancy and in the prevention and treatment of threatened and idiopathic recurrent miscarriage.

The experts also collated information on progestogens currently approved by the Saudi Food and Drug Administration (SFDA) for the treatment of threatened and idiopathic recurrent miscarriage. A literature review was conducted using PubMed. Articles were short-listed based on title and then abstracts were reviewed for relevancy. Only articles published in English were reviewed. The expert panel presented all collated information during the second meeting and used it as a basis for the position statements presented within this paper.

This paper will outline recommendations for using progestogens in threatened and idiopathic recurrent miscarriage, 
in Saudi Arabia. This document is intended as a reference for local general physicians, obstetricians/gynecologists, and fertility specialists for the management of the aforementioned patients. However, physicians are required to manage patients based on the best available evidence and using their clinical judgment and should also take factors such as patient characteristics, drug profile, and available resources into consideration.

\section{Review Summary}

What Progestogens Are Currently

Available For The Treatment Of Threatened And Idiopathic Recurrent

\section{Miscarriage?}

At present, the SFDA has registered only two of the four products listed in Table 2 for the treatment of threatened and idiopathic recurrent miscarriage, both are progestogens. It is important that hormonal treatment prescriptions are limited to those indicated for the treatment of threatened or recurrent miscarriage by the SFDA.

\section{What Is The Role Of Oral Progestogens} In The Prevention And Treatment Of Threatened And Idiopathic Recurrent

\section{Miscarriage?}

Oral Micronized Progesterone

Available data suggest that oral micronized progesterone may have a role in preterm labor ${ }^{12-15}$ but not in threatened or recurrent miscarriage.

\section{Dydrogesterone (Oral Progestogen)}

\section{Threatened Miscarriage}

Based on data from recent systematic reviews and metaanalyses, oral dydrogesterone effectively prevents miscarriage in pregnant women experiencing threatened miscarriage. ${ }^{16-18}$ The meta-analysis by Carp et al, which collated data from five randomized trials including 660 patients, reported that the miscarriage rate was $13 \%$ in women on dydrogesterone versus $24 \%$ in the control group (odds ratio [OR] 0.47, 95\% confidence interval [CI] $0.31-0.7,11 \%$ absolute reduction in miscarriage rate). ${ }^{16}$ Carp et al concluded that the $47 \%$ reduction in the odds of miscarriage observed with dydrogesterone compared with standard of care was indicative of real treatment effect. ${ }^{16}$ A more recent study by Lee et al that collated data from nine randomized trials including 913 patients (322 on dydrogesterone, 213 vaginal progesterone, and 378 control) reported that the incidence of miscarriage was significantly lower in the oral dydrogesterone group than in the control group $(11.7 \%$ vs $22.6 \%$; OR $0.43 ; 95 \%$ CI $\left.0.26-0.71 ; P=0.001 ; I^{2} 0 \%\right) .{ }^{17}$ Similar findings were reported by Wahabi et al: oral progestogens (dydrogesterone and micronized progesterone) were found to reduce the rate of miscarriage compared with no treatment (risk ratio [RR] 0.57; 95\% CI 0.38-0.85; three trials; 408 patients). ${ }^{19}$ Wang et al pooled data from eight randomized controlled trials, including 845 women with threatened miscarriage, and reported that women receiving dydrogesterone were at a lower risk of miscarriage (RR $0.49,95 \%$ CI $0.33-0.75)$ than women on natural progesterone (RR 0.69, 95\% CI 0.40-1.19). ${ }^{18}$ Furthermore, women treated with oral progestogens demonstrated a lower risk of miscarriage (RR $0.55,95 \%$ CI $0.38-0.79$ ) than those on vaginal progestogens (RR $0.58,95 \% \mathrm{CI}$ $0.28-1.21){ }^{18}$

Four recent clinical trials have reported beneficial effects with dydrogesterone in threatened miscarriage. ${ }^{20-23}$ In a study by El-Zibdeh and Yousef, 146 women presenting with mild-to-moderate vaginal bleeding during the first trimester were randomized to $10 \mathrm{mg}$ oral dydrogesterone twice daily $(n=86)$ or no treatment $(n=60) .{ }^{20}$ The incidence of miscarriage was found to be $17.5 \%$ with dydrogesterone versus $25 \%$ with no treatment $(P<0.05){ }^{20}$ Another open-label study reported that both dydrogesterone $(n=59)$ and micronized progesterone $(n=59)$ effectively reduced the extent of bleeding within 4-10 days, with comparable miscarriages rates. ${ }^{21}$ Furthermore, it was

Table 2 Progestogens Currently Available For The Treatment Of Threatened (TM) And Idiopathic Recurrent Miscarriage (RM) In Saudi Arabia

\begin{tabular}{|l|l|l|l|l|}
\hline Generic Name & Trade Name & Unit Strength & Route Of Administration & Indicated For TM And RM \\
\hline Hydroxyprogesterone caproate & Proluton Depot & $250 / 500 \mathrm{mg} / \mathrm{mL}$ & Intramuscular injection & Yes \\
Dydrogesterone & Duphaston & $10 \mathrm{mg}$ & Oral tablet & Yes \\
Progesterone & Cyclogest & $200 / 400 \mathrm{mg}$ & Vaginal pessaries & No \\
Progesterone & Endometrin & $100 \mathrm{mg}$ & Vaginal tablet & No \\
\hline
\end{tabular}


found that patients with low progesterone $(<35 \mathrm{nmol} / \mathrm{L})$ were 23 times more likely to experience a miscarriage than women with high progesterone $(\geq 35 \mathrm{nmol} / \mathrm{L}$ ) (OR 23.8 ; 95\% CI $6.5-86.6 ; P<0.0001) .{ }^{21}$ Overall both treatments were tolerated well, although drowsiness was experienced by a greater number of patients on micronized progesterone compared with dydrogesterone $(P=$ $0.003) .{ }^{21}$ Pandian reported that the rate of continuing pregnancy beyond 20 weeks was statistically higher with dydrogesterone $(87.5 \%)$ versus conservative management (71.6\%) $(P<0.05) .{ }^{23}$ The rate of miscarriage was also lower with dydrogesterone versus control $(12.5 \%$ vs $28.4 \% ; P<0.05$ ), with no differences in rates of cesarean section, placenta previa, antepartum hemorrhage, preterm labor, pregnancy-induced hypertension, or low birth weight $\left(<2500\right.$ g) babies. ${ }^{23}$ In a similar study by Omar et al, the rate of continuing pregnancy beyond 20 weeks was significantly higher with dydrogesterone versus conservative treatment (95.9\% vs $86.3 \%$; OR 3.773 ; $95 \%$ CI $1.009-14.108 ; P=$ $0.037) .{ }^{22}$ In terms of safety, no intrauterine deaths, congenital abnormalities, or pregnancy-related complications were reported with dydrogesterone. ${ }^{20,23}$

\section{Idiopathic Recurrent Miscarriage}

Data from two recent systematic reviews and meta-analyses showed that dydrogesterone could be effectively used to prevent miscarriage in women with a history of idiopathic recurrent miscarriage. ${ }^{24,25}$ Carp collated data from three studies, including 509 patients, and reported that the rate of miscarriage with dydrogesterone was lower than with control ( $10.5 \%$ vs $23.5 \%$; OR 0.29 ; $95 \%$ CI $0.13-0.65 ; 13 \%$ absolute reduction in miscarriage). ${ }^{24}$ Saccone et al collated data from 10 trials, 1586 patients, and reported that women randomized to receive progestogens in the first trimester and before 16 weeks of gestation had a lower risk of recurrent miscarriage (RR 0.72, 95\% CI 0.53-0.97) and higher rate of live birth (RR 1.07, 95\% CI 1.02-1.15) versus control/placebo. ${ }^{25}$

Looking at clinical trial data, Kumar et al reported that the risk of miscarriage after three miscarriages was 2.4 times higher with placebo than dydrogesterone (RR 2.4; 95\% CI 1.3-5.9). ${ }^{26}$ Both mean gestational age at delivery and birth weight were higher with dydrogesterone compared with placebo. ${ }^{26}$ In another study, dydrogesterone was found to significantly reduce the rate of miscarriage versus no treatment $(13 \%$ vs $29 \% ; P=0.028)$ with no reports of pregnancy complications or congenital abnormalities when given to women with history of idiopathic recurrent miscarriages. ${ }^{27}$
There are few reports of side effects in mothers taking dydrogesterone. Some studies have reported drowsiness, nausea and vomiting, although such symptoms might be associated with the pregnancy itself. ${ }^{16}$

Recommendation 1: Oral progestogens, namely dydrogesterone, are well tolerated and effectively reduce miscarriages in women at risk of threatened or idiopathic recurrent miscarriages.

\section{What Is The Role Of Vaginal Progestogens In The Prevention And Treatment Of Threatened And Idiopathic} Recurrent Miscarriage?

Data on the efficacy and safety of vaginal progestogens are limited. A single-blind study by Yassaee et al that included 60 pregnant women with threatened miscarriage reported that progesterone suppositories $(400 \mathrm{mg}$ ) reduced the number of miscarriages compared with control (6 vs 10 cases); however, this difference was not statistically significant. ${ }^{28}$ In a single-center, randomized, double-blind study including 50 women with a previous diagnosis of inadequate luteal phase and threatened miscarriage, vaginal progesterone gel (Crinone 8\%) was found to help reduce pain and the frequency of uterine contractions within 5 days of administration $(P<0.005)$, with a reduction in the rate of miscarriage after 60 days $(P<0.05)$, compared with placebo. ${ }^{29}$ More recently, a large randomized trial found that micronized vaginal progesterone was no better than placebo for the treatment of threatened miscarriage. ${ }^{30}$ However, the authors cautioned that other formulations of progestational agents have different molecular structures and therefore potentially different mechanisms of actions and pharmacologic features.

The multicenter, randomized, double-blind, placebocontrolled PROMISE study exploring the effect of micronized vaginal progesterone (400 $\mathrm{mg}$ capsules) in women with a history of unexplained recurrent miscarriage $(\mathrm{n}=$ 836; 404 progesterone, 432 placebo) did not find any benefit of vaginal progesterone in improving rates of live birth, clinical pregnancy between 6 and 8 weeks of gestation, ongoing pregnancy at 12 weeks of gestation, miscarriage, ectopic pregnancy, stillbirth, neonatal survival, or neonatal congenital anomalies. ${ }^{31}$ In contrast, in a similar study, Ismail et al reported that vaginal progesterone (400 $\mathrm{mg}$ pessaries) significantly reduced the rate of miscarriage compared with placebo $(12.4 \%$ vs $23.3 \% ; P=0.001)$ in addition to an improvement in live birth rate (91.6 vs 
$77.4 \%$ ) and continuation of pregnancy beyond 20 weeks (87.6 vs $76.7 \%$ ), both of which were statistically significant $(P<0.05) .{ }^{32}$ However, a recent Cochrane review, which included data from the Ismail study, demonstrated no difference between the incidences of recurrent miscarriage in patients receiving placebo $(n=763)$ and patients receiving vaginal progestogen $(n=738)$, with a $R R$ of 0.73 (95\% CI 0.40-1.31). ${ }^{33}$

Guidelines published by ESHRE, ${ }^{10}$ European Progestin Club (EPC), ${ }^{34}$ the German Society of Gynecology and Obstetrics (DGGG), Austrian Society of Gynecology and Obstetrics (ÖGGG), and Swiss Society of Gynecology and Obstetrics (SGGG) ${ }^{35}$ confirm that vaginal progesterone has no beneficial effect in early pregnancy and does not improve live birth rates in women with unexplained recurrent miscarriage and therefore cannot be recommended for routine use in the treatment of threatened or recurrent miscarriage.

Recommendation 2: Available evidence is insufficient to recommend the use of vaginal progestogens (capsule, suppository, micronized, or gel) for the treatment of threatened or recurrent miscarriage.

\section{What Is The Role Of Injectable Progestogens In The Prevention And Treatment Of Threatened And Idiopathic Recurrent Miscarriage?}

Many studies refer to the benefit of intramuscular progestogens for luteal-phase support and for treating preterm birth, ${ }^{36-42}$ but not to prevent/treat threatened or recurrent miscarriage. Only one randomized controlled study, by Beigi et al, reported that the risk of preterm labor in pregnant women with threatened miscarriage at $<34$ weeks' gestation was similar in intramuscular $(8.6 \%)$ and vaginal $(6.52 \%)$ progesterone groups [RR $1.31 ; 95 \%$ CI $0.47-3.66 ; P=0.59]^{43}$

Recommendation 3: There is insufficient evidence to support the use of injectable progestogens in miscarriage prevention and treatment.

\section{What Is The Role Of Combination Treatment (Oral And/Or Vaginal And/Or Injectable) In The Prevention And Treatment Of Threatened And Idiopathic Recurrent Miscarriage?}

There are no published articles assessing the efficacy and safety of progestogens in combination administered through different routes. Furthermore, the uterus is a hormone- sensitive organ that responds to the presence of estrogen and progesterone, each binding to their cognate receptors (ESR1 and PGR, respectively) and working in concert to establish and maintain pregnancy. ${ }^{44}$ Disruption to this balance may increase the likelihood of miscarriage by lowering the number of available progesterone receptors and/or estrogen receptors within the endometrium ${ }^{45}$ or by the dysregulation of gene transcription and uterine biology. ${ }^{46}$

Recommendation 4: There is no evidence to support the use of combination progestogens in the prevention and treatment of threatened and idiopathic recurrent miscarriage. Progestogen monotherapy administered in the appropriate dose is recommended.

\section{Are The Available Progestogens Safe In Early Pregnancy?}

Clinical studies of oral and vaginal routes of administration are associated with acceptable and minimal side effects, $6,17,31,36,47,48$ with fatigue, fluid retention, lipid level alterations, dysphoria, hypercoagulant states, and increased androgenicity reported most commonly. ${ }^{49}$ Natural progestogens are reported to have milder side effects, with oral micronized natural progestogens having fewer side effects than natural progesterones. ${ }^{49}$ However, given the poor bioavailability of oral micronized progesterone, high doses may be required, which may result in drowsiness $^{20}$ and liver toxicity. ${ }^{20,26}$

Dydrogesterone, a progestogen that is highly selective for the progesterone receptor, lacks estrogenic, androgenic, anabolic, and corticoid properties, ${ }^{26,50}$ most studies report no significant side effects ${ }^{16,24}$ including no masculinization of the female fetus ${ }^{27}$ or congenital abnormalities. ${ }^{20,23}$ In comparison with micronized progesterone, dydrogesterone was found to cause significantly fewer cases of drowsiness $(P=$ $0.003)$, with no differences in nausea, vomiting, giddiness, bloating, diarrhea, or headache. ${ }^{21}$ Astoundingly, although 38 million women were treated with dydrogesterone between 1977 and 2005, with >10 million fetuses exposed in utero, only 28 cases of potential links between its use and congenital birth defects were reported. ${ }^{51}$ Thus, dydrogesterone is very unlikely to be teratogenic. ${ }^{51,52}$ Furthermore, dydrogesterone has been used for a variety of indications worldwide in an estimated 113 million women since 1960, with approximately 20 million fetuses being exposed in utero, which demonstrates its continued favorable safety and tolerability profile during pregnancy. ${ }^{50}$ 
Intramuscular progestogen is commonly associated with injection-site reactions, including soreness, swelling, itching, and bruising, ${ }^{53}$ with daily injections associated with pain at injection site and local abscess formation. ${ }^{50}$

Carmichael et al reported that intake of progestogens during pregnancy was associated with an increased risk of hypospadias, with an OR of 3.7 (95\% CI 2.3-6.0).${ }^{54}$ Looking at data published before 1990, two studies report no congenital abnormalities with use of progestogens (vaginal and intramuscular) during pregnancy. ${ }^{55,56}$ In 2008, the Practice Committee of the American Society for Reproductive Medicine stated that there is no evidence to indicate that supplementation with progestogens during early pregnancy poses any significant risk of hypospadias or other types of birth defect. ${ }^{57}$ For treatment during pregnancy, progestogens with the least androgenic or with anti-androgenic properties are particularly sought because they are expected to cause the least alterations in the sexual development of a fetus. ${ }^{58}$ Clinical studies in which a limited number of women were treated with dydrogesterone early in pregnancy have not shown any increase in the risk of hypospadias. The Cochrane Reviews on the role of progestogen treatment during pregnancy ${ }^{19,59}$ and the meta-analysis by Carp $^{16}$ concluded that no safety issues were suspected when comparing newborns of mothers who had received progestogens with those who did not, including no increased risk of congenital abnormalities.

Recommendation 5: Progestogens are generally well tolerated, with minimal side effects. Although progestogen administration during the first trimester was linked to hypospadias risk, recent and more thorough reports have not shown an increase in the rate of hypospadias.

\section{Position Statements}

\section{Threatened Miscarriage}

1. For women presenting with a clinical diagnosis of threatened miscarriage, dydrogesterone may reduce the rate of miscarriage.

2. Oral dydrogesterone should be offered. Manufacturer dosage: $40 \mathrm{mg}$ loading, then $30 \mathrm{mg}$ once daily until symptoms (bleeding) remit. If symptoms persist/ recur, increase dose by $10 \mathrm{mg}$ three times a day. Maintain effective dose for 1 week after symptoms have ceased and then gradually reduce dose. Immediately resume treatment at effective dose, if symptoms recur.

\section{Recurrent Miscarriage}

1. Thorough investigations are warranted to rule out other causes of miscarriage. Once ruled out, a diagnosis of idiopathic recurrent miscarriage is confirmed.

2. For women presenting with a clinical diagnosis of idiopathic recurrent miscarriage (having experienced two or more), there is a reduction in the rate of miscarriage with the use of dydrogesterone.

3. Dydrogesterone should be administered as early as possible, at the diagnosis of pregnancy or during the luteal phase, in stimulated cycles.

4. Oral dydrogesterone should be offered. Manufacturer dosage: 10-20 mg daily, until the 20th week of pregnancy. Treatment should preferably start before conception. If symptoms of threatened miscarriage occur during treatment, continue treatment as stated for that indication.

\section{Acknowledgments}

The authors would like to thank Abbott for providing funding for medical writing assistance. Medical writing support in the development of this manuscript was provided by Leris D'Costa of OPEN Health Dubai, funded by Abbott, Saudi Arabia. Abbott played no role in the collection, analysis, and interpretation of data or in the preparation of this manuscript. The consensus meetings held on November 15, 2018, and January 31, 2019, in Jeddah, Saudi Arabia, were sponsored by Abbott, Saudi Arabia. Sponsorship included travel expenses and an honorarium for participating authors.

\section{Author Contributions}

Hisham Arab was involved in the conception and execution of the project and helped outline and draft the manuscript. All authors were involved in the acquisition and interpretation of the data, provided critical comments and concepts during the consensus meeting that were incorporated into the manuscript. All authors conducted literature reviews in support of the recommendations; participated in the consensus meeting for generating recommendations; and contributed to the development, drafting or revising, and finalization of the manuscript. All authors approved the final submitted version of the manuscript. All authors agree to be accountable for all aspects of the work in ensuring that questions related to the accuracy or integrity of any part of the work are appropriately investigated and resolved. 


\section{Disclosure}

Hisham Arab has received speaker honoraria from Bayer, Abbott, and MSD, and advisor honoraria from Vifor and Sanofi. The authors report no other conflicts of interest in this work.

\section{References}

1. Macklon NS, Geraedts JP, Fauser BC. Conception to ongoing pregnancy: the 'black box' of early pregnancy loss. Hum Reprod Update. 2002;8(4):333-343. doi:10.1093/humupd/8.4.333

2. Larsen EC, Christiansen OB, Kolte AM, Macklon N. New insights into mechanisms behind miscarriage. BMC Med. 2013;11:154 doi:10.1186/1741-7015-11-154

3. Griebel CP, Halvorsen J, Golemon TB, Day AA. Management of spontaneous abortion. Am Fam Physician. 2005;72(7):1243-1250.

4. Zhang HX, Qin YZ, Liu WH, Hao R. Hypothyroidism and firsttrimester spontaneous miscarriages. Clin Exp Obstet Gynecol. 2014;41(2):182-185.

5. Chang K, Lubo Z. Review article: steroid hormones and uterine vascular adaptation to pregnancy. Reprod Sci. 2008;15(4):336-348. doi: $10.1177 / 1933719108317975$

6. Di Renzo GC, Giardina I, Clerici G, Brillo E, Gerli S. Progesterone in normal and pathological pregnancy. Horm Mol Biol Clin Investig. 2016;27(1):35-48. doi:10.1515/hmbci-2016-0038

7. Czyzyk A, Podfigurna A, Genazzani AR, Meczekalski B. The role of progesterone therapy in early pregnancy: from physiological role to therapeutic utility. Gynecol Endocrinol. 2017;33(6):421-424. doi:10. 1080/09513590.2017.1291615

8. Raghupathy R, Al Mutawa E, Makhseed M, Azizieh F, SzekeresBartho J. Modulation of cytokine production by dydrogesterone in lymphocytes from women with recurrent miscarriage. BJOG. 2005;112(8):1096-1101. doi:10.1111/j.1471-0528.2005.00633.x

9. Mincheva-Nilsson L. Pregnancy and gamma/delta T cells: taking on the hard questions. Reprod Biol Endocrinol. 2003;1:120. doi:10.1186/ 1477-7827-1-120

10. ESHRE Early Pregnancy Guidline Development Group. Recurrent pregnancy loss. Guideline of the European Society of Human Reproduction and Embryology. Available from: https://www.eshre. eu/Guidelines-and-Legal/Guidelines/Recurrent-pregnancy-loss.aspx. Accessed October, 152018.

11. Arab H, Alsofayan H, Alharbi A, Sendy S, Abduljabbar H; The Saudi Obstetrics and Gynecological Society (SOGS). National guidelines for the prevention and treatment of miscarriage. Saudi $J$ Obstet Gynecol. 2014;15(1):40-63.

12. Pustotina O. Effectiveness of dydrogesterone, 17-OH progesterone and micronized progesterone in prevention of preterm birth in women with a short cervix. J Matern Fetal Neonatal Med. 2018;31(14):1830-1838. doi:10.1080/14767058.2017.1330406

13. Kececioglu M, Tokmak A, Kececioglu TS, Akselim B, Karakaya BK, Tasci Y. Does progesterone therapy increase nuchal translucency in women with threatened miscarriage? Ginekol Pol. 2016;87(5):390394. doi:10.5603/GP.2016.0010

14. Rai P, Rajaram S, Goel N, Ayalur Gopalakrishnan R, Agarwal R, Mehta S. Oral micronized progesterone for prevention of preterm birth. Int $J$ Gynaecol Obstet. 2009;104(1):40-43. doi:10.1016/j.jigo.2008.08.029

15. Glover MM, McKenna DS, Downing CM, Smith DB, Croom CS, Sonek JD. A randomized trial of micronized progesterone for the prevention of recurrent preterm birth. Am J Perinatol. 2011;28 (5):377-381. doi:10.1055/s-0031-1274509

16. Carp H. A systematic review of dydrogesterone for the treatment of threatened miscarriage. Gynecol Endocrinol. 2012;28(12):983-990. doi:10.3109/09513590.2012.702875
17. Lee HJ, Park TC, Kim JH, Norwitz E, Lee B. The influence of oral dydrogesterone and vaginal progesterone on threatened abortion: a systematic review and meta-analysis. Biomed Res Int. 2017;2017:3616875. doi:10.1155/2017/3616875

18. Wang XX, Luo Q, Bai WP. Efficacy of progesterone on threatened miscarriage: difference in drug types. $J$ Obstet Gynaecol Res. 2019;45(4):794-802. doi:10.1111/jog.13909

19. Wahabi HA, Fayed AA, Esmaeil SA, Bahkali KH. Progestogen for treating threatened miscarriage. Cochrane Database Syst Rev. 2018;8: CD005943.

20. El-Zibdeh MY, Yousef LT. Dydrogesterone support in threatened miscarriage. Maturitas. 2009;65 Suppl 1:S43-S46. doi:10.1016/j. maturitas.2009.11.013

21. Siew JYS, Allen JC, Hui CYY, et al. The randomised controlled trial of micronised progesterone and dydrogesterone (TRoMaD) for threatened miscarriage. Eur J Obstet Gynecol Reprod Biol. 2018;228:319324. doi:10.1016/j.ejogrb.2018.07.028

22. Omar MH, Mashita MK, Lim PS, Jamil MA. Dydrogesterone in threatened abortion: pregnancy outcome. J Steroid Biochem Mol Biol. 2005;97(5):421-425. doi:10.1016/j.jsbmb.2005.08.013

23. Pandian RU. Dydrogesterone in threatened miscarriage: a Malaysian experience. Maturitas. 2009;65(Suppl 1):S47-S50. doi:10.1016/j. maturitas.2009.11.016

24. Carp H. A systematic review of dydrogesterone for the treatment of recurrent miscarriage. Gynecol Endocrinol. 2015;31(6):422-430. doi:10.3109/09513590.2015.1006618

25. Saccone G, Schoen C, Franasiak JM, Scott RT Jr., Berghella V. Supplementation with progestogens in the first trimester of pregnancy to prevent miscarriage in women with unexplained recurrent miscarriage: a systematic review and meta-analysis of randomized, controlled trials. Fertil Steril. 2017;107(2):430-438 e433. doi:10.1016/j. fertnstert.2016.10.031

26. Kumar A, Begum N, Prasad S, Aggarwal S, Sharma S. Oral dydrogesterone treatment during early pregnancy to prevent recurrent pregnancy loss and its role in modulation of cytokine production: a double-blind, randomized, parallel, placebo-controlled trial. Fertil Steril. 2014;102 (5):1357-1363 e1353. doi:10.1016/j.fertnstert.2014.07.1251

27. El-Zibdeh MY. Dydrogesterone in the reduction of recurrent spontaneous abortion. J Steroid Biochem Mol Biol. 2005;97(5):431-434. doi:10.1016/j.jsbmb.2005.08.007

28. Yassaee F, Shekarriz-Foumani R, Afsari S, Fallahian M. The effect of progesterone suppositories on threatened abortion: a randomized clinical trial. J Reprod Infertil. 2014;15(3):147-151.

29. Palagiano A, Bulletti C, Pace MC, DEZ D, Cicinelli E, Izzo A. Effects of vaginal progesterone on pain and uterine contractility in patients with threatened abortion before twelve weeks of pregnancy. Ann N Y Acad Sci. 2004;1034:200-210. doi:10.1196/ annals. 1335.022

30. Coomarasamy A, Devall AJ, Cheed V, et al. A randomized trial of progesterone in women with bleeding in early pregnancy. $N$ Engl $J$ Med. 2019;380(19):1815-1824. doi:10.1056/NEJMoa1813730

31. Coomarasamy A, Williams H, Truchanowicz E, et al. PROMISE: first-trimester progesterone therapy in women with a history of unexplained recurrent miscarriages - a randomised, double-blind, placebo-controlled, international multicentre trial and economic evaluation. Health Technol Assess. 2016;20(41):1-92. doi:10.3310/ hta20410

32. Ismail AM, Abbas AM, Ali MK, Amin AF. Peri-conceptional progesterone treatment in women with unexplained recurrent miscarriage: a randomized double-blind placebo-controlled trial. J Matern Fetal Neonatal Med. 2018;31(3):388-394. doi:10.1080/ 14767058.2017.1286315

33. Haas DM, Hathaway TJ, Ramsey PS. Progestogen for preventing miscarriage in women with recurrent miscarriage of unclear etiology. Cochrane Database Syst Rev. 2018;10:CD003511. 
34. Schindler AE, Carp H, Druckmann R, et al. European progestin club guidelines for prevention and treatment of threatened or recurrent (habitual) miscarriage with progestogens. Gynecol Endocrinol. 2015;31(6):447-449. doi:10.3109/09513590.2015.1017459

35. Toth B, Wurfel W, Bohlmann M, et al. Recurrent miscarriage: diagnostic and therapeutic procedures. Guideline of the DGGG, OEGGG and SGGG (S2k-Level, AWMF Registry Number 015/050). Geburtshilfe Frauenheilkd. 2018;78(4):364-381. doi:10.1055/a-0586-4568

36. Saccone G, Khalifeh A, Elimian A, et al. Vaginal progesterone vs intramuscular 17alpha-hydroxyprogesterone caproate for prevention of recurrent spontaneous preterm birth in singleton gestations: systematic review and meta-analysis of randomized controlled trials. Ultrasound Obstet Gynecol. 2017;49(3):315-321. doi:10.1002/ uog. 17245

37. Samson FD, Merriman AL, Tate DL, Apostolakis-Kyrus K, Gomez LM. Adjuvant administration of 17-alpha-hydroxy-progesterone caproate in women with three or more second trimester pregnancy losses undergoing cervical cerclage is no more effective than cerclage alone. $J$ Perinat Med. 2018;46(2):155-161. doi:10.1515/jpm-2017-0074

38. Duan L, Yan D, Zeng W, Yang X, Wei Q. Effect of progesterone treatment due to threatened abortion in early pregnancy for obstetric and perinatal outcomes. Early Hum Dev. 2010;86(1):41-43. doi:10.1016/j.earlhumdev.2009.12.007

39. Haghighi L, Rashidi M, Najmi Z, et al. Comparison of intramuscular progesterone with oral nifedipine for treating threatened preterm labor: a randomized controlled trial. Med J Islam Repub Iran. 2017;31:56. doi:10.14196/mjiri.31.56

40. Miles RA, Paulson RJ, Lobo RA, Press MF, Dahmoush L, Sauer MV. Pharmacokinetics and endometrial tissue levels of progesterone after administration by intramuscular and vaginal routes: a comparative study. Fertil Steril. 1994;62(3):485-490. doi:10.1016/s0015-0282(16) 56935-0

41. Smitz J, Devroey P, Faguer B, Bourgain C, Camus M, Van Steirteghem AC. A prospective randomized comparison of intramuscular or intravaginal natural progesterone as a luteal phase and early pregnancy supplement. Hum Reprod. 1992;7(2):168-175. doi:10.1093/oxfordjournals.humrep.a137611

42. Sohn SH, Penzias AS, Emmi AM, et al. Administration of progesterone before oocyte retrieval negatively affects the implantation rate. Fertil Steril. 1999;71(1):11-14. doi:10.1016/s0015-0282(98)00404-x

43. Beigi A, Esmailzadeh A, Pirjani R. Comparison of risk of preterm labor between vaginal progesterone and 17-alpha-hydroxy-progesterone caproate in women with threatened abortion: a randomized clinical trial. Int J Fertil Steril. 2016;10(2):162-168.

44. Wetendorf M, DeMayo FJ. Progesterone receptor signaling in the initiation of pregnancy and preservation of a healthy uterus. Int J Dev Biol. 2014;58(2-4):95-106. doi:10.1387/ijdb.140069mw

45. Carranza-Lira S, Blanquet J, Tserotas K, Calzada L. Endometrial progesterone and estradiol receptors in patients with recurrent early pregnancy loss of unknown etiology-preliminary report. Med Sci Monit. 2000;6(4):759-762.
46. DeMayo FJ, Zhao B, Takamoto N, Tsai SY. Mechanisms of action of estrogen and progesterone. Ann N Y Acad Sci. 2002;955:48-59. doi:10.1111/j.1749-6632.2002.tb02765.x

47. Lucovnik M, Kuon RJ, Chambliss LR, et al. Progestin treatment for the prevention of preterm birth. Acta Obstet Gynecol Scand. 2011;90 (10):1057-1069. doi:10.1111/j.1600-0412.2011.01178.x

48. Rode L, Klein K, Nicolaides KH, Krampl-Bettelheim E, Tabor A, Group P. Prevention of preterm delivery in twin gestations (PREDICT): a multicenter, randomized, placebo-controlled trial on the effect of vaginal micronized progesterone. Ultrasound Obstet Gynecol. 2011;38(3):272-280. doi:10.1002/uog.9093

49. Goletiani NV, Keith DR, Gorsky SJ. Progesterone: review of safety for clinical studies. Exp Clin Psychopharmacol. 2007;15(5):427-444. doi:10.1037/1064-1297.15.5.427

50. Tournaye H, Sukhikh GT, Kahler E, Griesinger G. A Phase III randomized controlled trial comparing the efficacy, safety and tolerability of oral dydrogesterone versus micronized vaginal progesterone for luteal support in in vitro fertilization. Hum Reprod. 2017;32 (5):1019-1027. doi:10.1093/humrep/dex023

51. Queisser-Luft A. Dydrogesterone use during pregnancy: overview of birth defects reported since 1977. Early Hum Dev. 2009;85(6):375377. doi:10.1016/j.earlhumdev.2008.12.016

52. Arab HA. An insight into early fetal loss. Obstet Gynecol. 2017;1 (2):67-69.

53. Meis PJ, Klebanoff M, Thom E, et al. Prevention of recurrent preterm delivery by 17 alpha-hydroxyprogesterone caproate. $N$ Engl J Med. 2003;348(24):2379-2385. doi:10.1056/NEJMoa035140

54. Carmichael SL, Shaw GM, Laurent C, Croughan MS, Olney RS, Lammer EJ. Maternal progestin intake and risk of hypospadias. Arch Pediatr Adolesc Med. 2005;159(10):957-962. doi:10.1001/archpedi. 159.10.957

55. Check JH, Rankin A, Teichman M. The risk of fetal anomalies as a result of progesterone therapy during pregnancy. Fertil Steril. 1986;45(4):575-577. doi:10.1016/s0015-0282(16)49292-7

56. Rock JA, Wentz AC, Cole KA, et al. Fetal malformations following progesterone therapy during pregnancy: a preliminary report. Fertil Steril. 1985;44(1):17-19. doi:10.1016/s0015-0282(16)48670-x

57. Practice Committee of the American Society for Reproductive M. Progesterone supplementation during the luteal phase and in early pregnancy in the treatment of infertility: an educational bulletin. Fertil Steril. 2008;89(4):789-792. doi:10.1016/j.fertnstert.2008.02. 012

58. Rizner TL, Brozic P, Doucette C, et al. Selectivity and potency of the retroprogesterone dydrogesterone in vitro. Steroids. 2011;76(6):607615. doi:10.1016/j.steroids.2011.02.043

59. Wahabi HA, Fayed AA, Esmaeil SA, Al Zeidan RA. Progestogen for treating threatened miscarriage. Cochrane Database Syst Rev. 2011; (12):CD005943

\section{Publish your work in this journal}

The International Journal of Women's Health is an international, peerreviewed open-access journal publishing original research, reports, editorials, reviews and commentaries on all aspects of women's healthcare including gynecology, obstetrics, and breast cancer. The manuscript management system is completely online and includes a very quick and fair peer-review system, which is all easy to use. Visit http://www.dovepress.com/testimonials.php to read real quotes from published authors. 